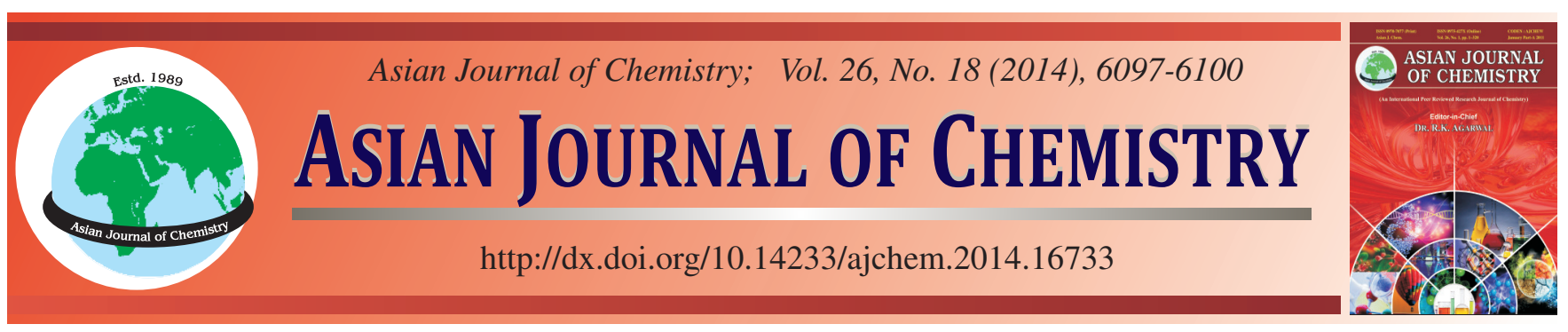

\title{
Study on Properties of Hydrophobically Associating Polymer in High Salinity Reservoirs
}

\author{
KaI Wang ${ }^{1, *}$, Caili Dai ${ }^{1, *}$, Wangwang Zhang ${ }^{3}$, Hailong $\mathrm{Chen}^{1}, \mathrm{HuI} \mathrm{Li}^{1}$, Lei Wang ${ }^{2}$ and Xiaoming $\mathrm{Wu}^{2}$
}

${ }^{1}$ College of Petroleum Engineering, China University of Petroleum (East China), Qingdao 266580, Shandong, P.R. China

${ }^{2}$ Drilling and Production Technology Institute of Liaohe Oilfield, Panjin 124010, Liaoning, P.R. China

${ }^{3}$ Yulin to Jinan Gas Pipeline Company, Jinan 250101, Shandong Province, P.R. China

*Corresponding authors: E-mail: wangkaiupc@163.com; daicl306@163.com

Received: 21 November 2013;

Accepted: 3 July 2014;

Published online: 1 September 2014;

AJC-15861

\begin{abstract}
Compared with the conventional partially hydrolyzed polyacrylamide, hydrophobically associating polymer performs better in high salinity reservoirs. In this paper, the variation of viscosity is studied under condition of different influencing factors such as concentration, salinity and temperature. The results show that the optimum applicable mass concentration, salinity and temperature is $2500-4000 \mathrm{mg} / \mathrm{L}$, $40500-80500 \mathrm{mg} / \mathrm{L}$ and $20-60^{\circ} \mathrm{C}$, respectively. Sandpacking flooding test and anti-shearing test are carried out under laboratory conditions. The results show that the hydrophobically associating polymer after being sheared also has ability to regain its viscosity and the incremental oil recovery obtained in high salinity is higher than conventional polymer flooding, which suggests that it has a wide application prospects in tertiary oil recovery.
\end{abstract}

Keywords: Hydrophobically associating polymer, Applicable condition, Tertiary oil recovery, High salinity, Antishearing.

\section{INTRODUCTION}

The application of water-soluble polymer is an economic way for enhanced oil recovery (EOR) $)^{1-3}$, which has already been successfully used in water flooding ${ }^{4-5}$. In the most enhanced oil recovery field application, one of the most important effects of these polymers is to increase the viscosity of the water solution. They can remarkably enlarge the sweep volume and enhance the sweep effective, thus highly increase the oil recovery by $8-10 \%$ higher than conventional water flooding.

Although the polymer flooding is a relatively mature tertiary oil recovery technology, the problems are also obvious during the process as following: (1) Viscosity of the polymer decreases by several factors during flowing such as shearing, thermal effect, bacterial action, hydrolysis and high metal ions, which influences the development effect of polymer flooding. (2) The polymer solution used in polymer flooding has certain function of profile modification. But its ability to control high permeability layer especially the extra-high permeable strata is limited. When blocks with high permeability layer especially the extra-high permeable strata are injected with polymer solution, the concentration of polymer produced from oil well is high, which not only affect the development effect but also results in environmental pollution. (3) There exists fingering phenomenon during the process of subsequent water flooding, which leads to the rapid increase of water cut and significantly decrease of oil production. As a consequence, a high concentration of the polymer is required in actual applications and hydrolyzed polyacrylamide (HPAM) is not suitable for oil reservoir with high temperature and high salinity nature. Thus the specific molecular structure indicates that HPAM can only be used in moderate temperature and salinity for enhanced oil recovery. All these disadvantages seriously retard the propagation of chemical flooding in China. With the tertiary oil recovery developing into the stage of high temperature and high salinity, the conventional water-soluble polymer can't meet the requirement in profile modification ${ }^{6}$. Hence, the research and development of the salt-resistant water-soluble polymers for enhancing oil recovery has become very urgent.

The hydrophobically associating polymer studied in this paper is similar to the hydrophobically associating watersoluable polymer (HAWP). It increases the viscosity of the system with the network structure formed by intermolecular association which leads to the formation of three-dimensional network. This association can increase the fluid mechanical volume which may lead to a significant increase of apparent viscosity $^{7-10}$. Therefore it has a strong effect on increasing the viscosity of the water solution, which shows that it improves the ability of profile modification and oil flooding. Adding small molecular electrolytes into water solution can increase the polarizability of the water solution and then reinforce the self-thickening ability. Thus the hydrophobically associating 
polymer can effectively improves the water-soluble polymer's ability in salt-resistant. Furthermore, the self-thickening effect can be regarded as a process of entropy increase, which means that as temperature increases, the self-thickening phenomenon also happens. The intermolecular association is favored when temperature increase in certain ranges which means the hydrophobically associating polymer should have higher temperature resistance than ordinary water-soluble polymers. The hydrophobically associating polymer also has superior properties in the aspect of salt-resistant, self-thickening and anti-shearing.

Although the rheology of the hydrophobically associating water-soluble polymer has been studied widely. All of their experiments are carried out without considering time factor. So viscosity of hydrophobically associating polymer in high salinity reservoir studied in this paper is not only theoretically significant but also practically meaningful.

\section{EXPERIMENTAL}

Hydrophobically associating polymer and sodium chloride (AR) were provided by Xilong Co. Ltd. China. Calcium chloride anhydrous (AR) was provided by Sinopharm Chemical Reagent Co. Ltd. A BROOK-FIELD PRO DV-II viscometer was used to measure the viscosity of polymer solutions.

\section{RESULTS AND DISCUSSION}

Characteristic properties of the hydrophobically associating polymer solution: Fig. 1 shows viscosity $v s$. polymer concentration of the hydrophobically associating polymer. It is clearly shown that the viscosity of hydrophobically associating polymer solution increases smoothly under $2500 \mathrm{mg} / \mathrm{L}$. However, the viscosity of the hydrophobically associating polymer solution increases rapidly with its concentration above $3000 \mathrm{mg} / \mathrm{L}$.

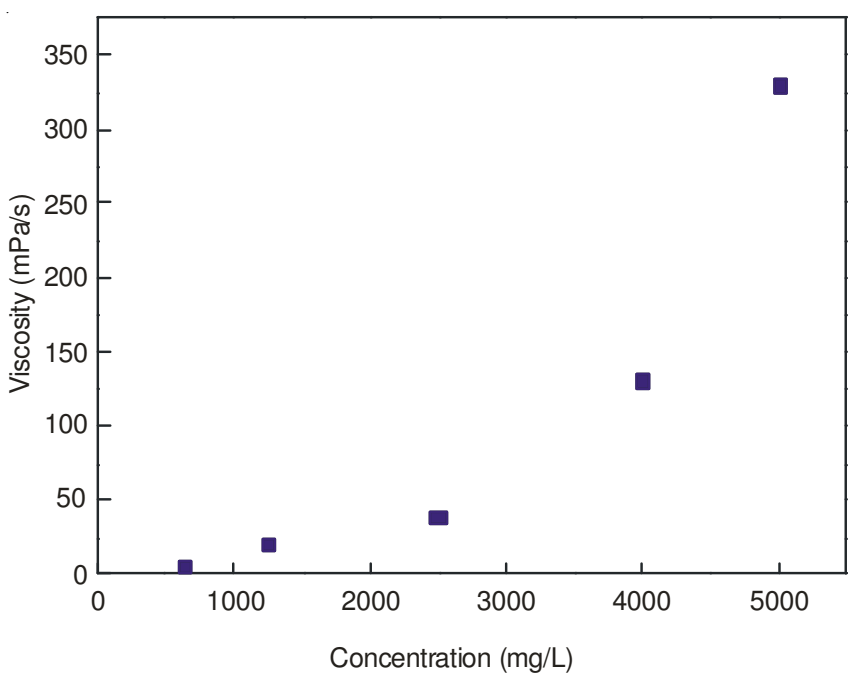

Fig. 1. Effect of hydrophobically associating polymer concentration on the viscosity of solution

The results mean that when the concentration is above $2500 \mathrm{mg} / \mathrm{L}$, the aggregation of hydrophobic groups happens and physical cross-linking takes place. The polymer concentration at this point is called the critical aggregation concentration $\left(\mathrm{C}^{*}\right)$. When hydrophobically associating polymer concentration was lower than $\mathrm{C}^{*}$, intra-action of polymer molecules was dominant and polymer chains were highly coiled. As a result, viscosity increases slowly with the increase of polymer concentration. When polymer concentration is close to, even higher than $C^{*}$, intermolecular association emerge and become strong, resulting viscosity increased sharply with the increase of polymer concentration.

Effects of salinity on the viscosity of hydrophobically associating polymer solution: Fig. 2 showed that when the salinity ranges from 40500 to $80500 \mathrm{mg} / \mathrm{L}$, the initial viscosity of hydrophobically associating polymer increases and forms a homogeneous solution in 3 to $4 \mathrm{~h}$.

However, with the salinity higher than $80500 \mathrm{mg} / \mathrm{L}$, the polymer can't be dissolved completely in water, which results in a pretty low viscosity as shown in Fig. 2 . When the attraction between polymer molecule and solvent is beyond the cohesion among polymer molecules, polymer can stretch thoroughly in the solvent. On the contrary, when the cohesion among polymer molecules is higher than the attraction between solvent and polymer molecules, polymer curls up in the solvent. With the adding of salt content, the attraction between solvent and the hydrophilic main chain of hydrophobically associating polymer decreases, which leads to the contraction of polymer molecules. It is a disadvantage for the formation of physical cross-linking network, which results in the no increase in viscosity of polymer solution or even insolubilization of the polymer. As a result, the salinity should be under $80500 \mathrm{mg} / \mathrm{L}$ in the following experiment.

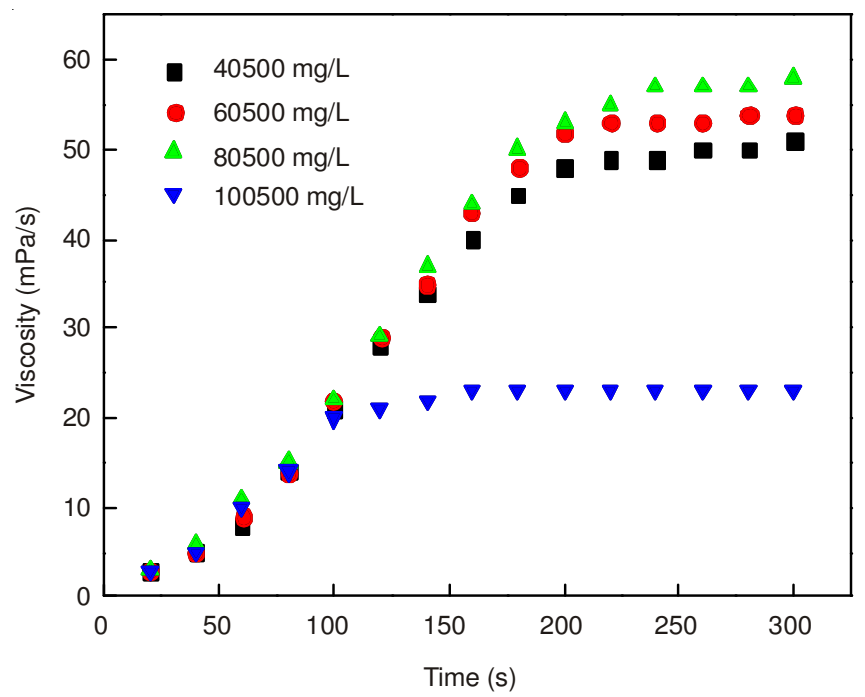

Fig. 2. Effect of salinity on the solubility of hydrophobically associating polymer solution

Fig. 3 reveals that the viscosity of polymer solution when salinity is 20500 or $40500 \mathrm{mg} / \mathrm{L}$ increases little. Viscosity of the hydrophobically associating polymer increases significantly when the salinity is 40500 or $80500 \mathrm{mg} / \mathrm{L}$. It is observed that to hydrophobically associating polymer, there also exists a critical salinity 10 under which there's no phenomenon of self-thickening. To some extent (the salinity under 80500 $\mathrm{mg} / \mathrm{L})$, the higher the salinity, the higher the stable viscosity of the hydrophobically associating polymer. 


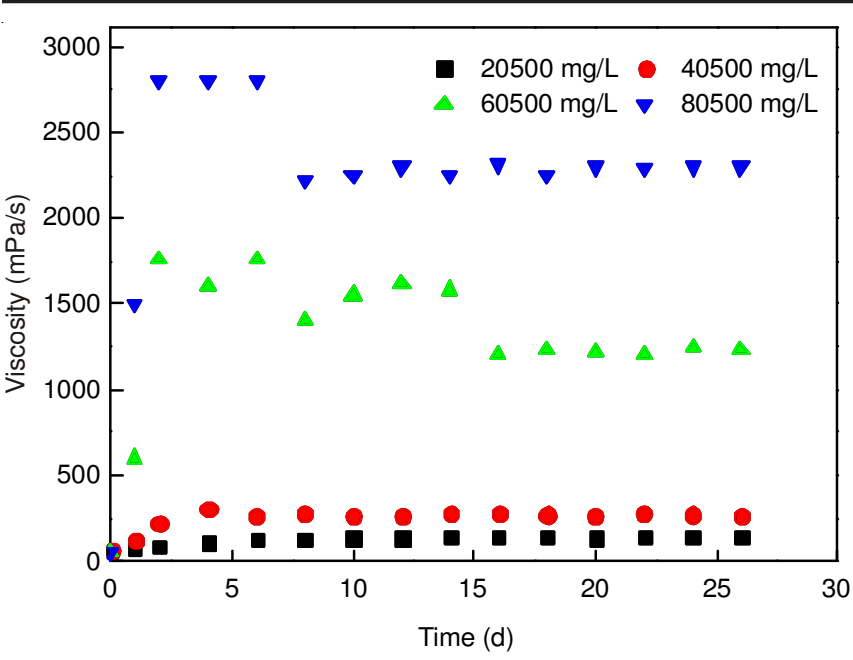

Fig. 3. Effect of salinity on the viscosity of polymer solution

Effects of mass concentration on the viscosity of hydrophobically associating polymer solution: Fig. 4 showed that the viscosity of polymer solution increases hardly when the mass fraction is under $2500 \mathrm{mg} / \mathrm{L}$. However, viscosity of the hydrophobically associating polymer increases significantly when the mass fraction is above $2500 \mathrm{mg} / \mathrm{L}$. The higher the mass fraction, the higher the stable viscosity of the hydrophobically associating polymer is. The effect is significant. The increase in viscosity of polymer solution is determined by three aspects. Firstly, as known, the conformation of the polymer molecular in solution is curly. When the mass fraction is above some value the viscosity increases sharply through the mutual entanglement among polymer molecules which leads to the formation of network structure. Secondly, strong intermolecular forces existing among polymer molecular with which the network structure forms when the distance among them is shorten to a certain value, which results in the increase in viscosity. Thirdly, to hydrophobically associating polymer, there exists a critical association concentration above which intermolecular association dominates, that results in the sharply increase of apparent viscosity. However, when the mass fraction is up to $5000 \mathrm{mg} / \mathrm{L}$, not only the stable viscosity reaches about $10000 \mathrm{mPa} \cdot \mathrm{s}$ but also the initial viscosity is about $200 \mathrm{mPa} \cdot \mathrm{s}$ which is disadvantageous on its injectivity.

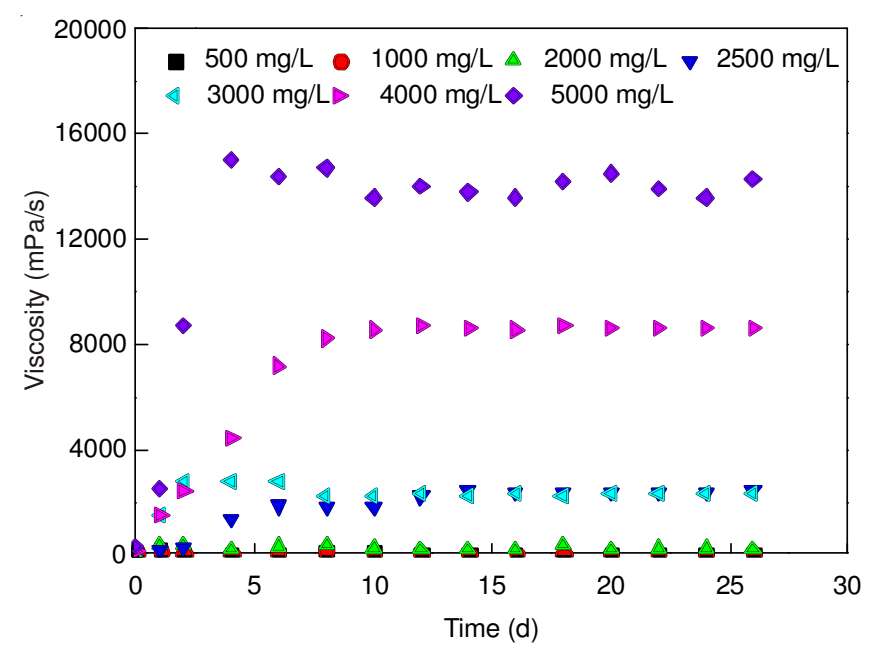

Fig. 4. Effect of polymer concentration on the viscosity of hydrophobically associating polymer solution
Effects of temperature on the viscosity of hydrophobically associating polymer solution: From Fig. 5, the selfthickening effect of polymer is significant from 20 to $60{ }^{\circ} \mathrm{C}$ and the stable viscosity is approximately $2500 \mathrm{mPa} \cdot \mathrm{s}$. With the further increase of temperature, the self-thickening effect gets worse. There is rarely phenomenon of self-thickening when the temperature is up to $80^{\circ} \mathrm{C}$. The reasons can be divided into 3 parts. Firstly, the rising of temperature results in the aggravation of molecular thermodynamic movement. The hydrated structure of the hydrophobic group is changed, that weakens the association among molecular chains. The increment of temperature also curls the polymer molecular, which also leads to the reduction of viscosity of the polymer solution. Thirdly, the interaction among hydrophobically associating polymer is a process of entropy-driven. With temperature going up, the entropy of the polymer system increases which leads to the enhancement of self-thickening ability. However, when the temperature beyond $40{ }^{\circ} \mathrm{C}$, the viscosity of solution drops with the rising of temperature.

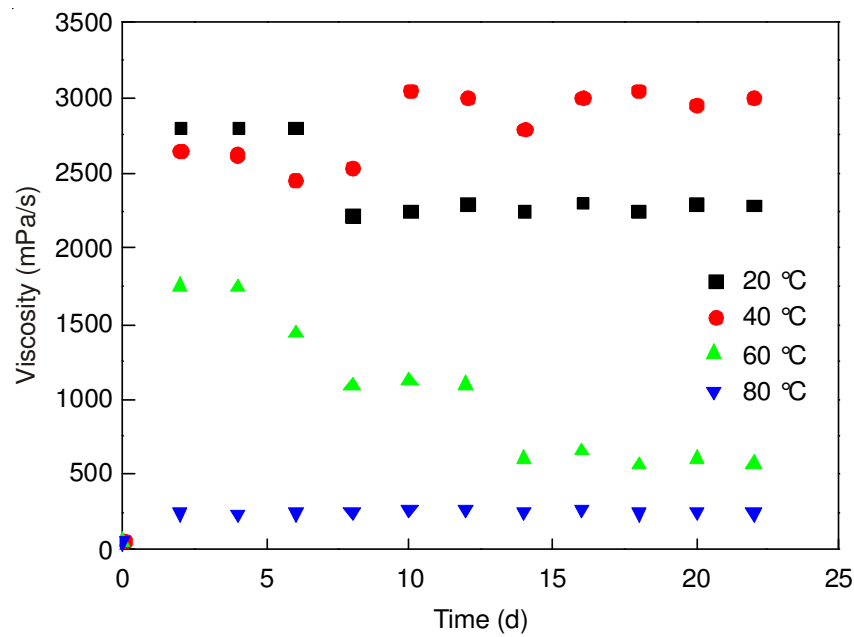

Fig. 5. Effect of temperature on the viscosity of hydrophobically associating polymer solution

Effects of shearing on the viscosity of hydrophobically associating polymer solution: Shearing has a significant influence on the viscosity of the polymer solution (Fig. 6). The longer the shearing time is, the lower the initial viscosity because of the destruction of molecular chains. Furthermore, the polymer after shearing also has the ability to regain its viscosity, which is critical to its practical application. The reason lies in that the shearing destroys structure of polymer molecular that leads to the reduction of viscosity. Yet because of the low molecular weight of the hydrophobically associating polymer, molecules are not sheared off. Only some or most of the physical network structure and supra-molecular aggregates are split up. Thus after shearing, molecular chains split up gather again to form the supra-molecular aggregate which results in the increase of its viscosity, which demonstrates its excellent property of shear-resistant.

Incremental oil recovery: The experimental flow chart is shown in Fig. 7. The steps for determining the oil recovery increment are as followings: (1) saturate water in sand-packed cores; (2) saturate crude oil in sand-packed cores; (3) water 


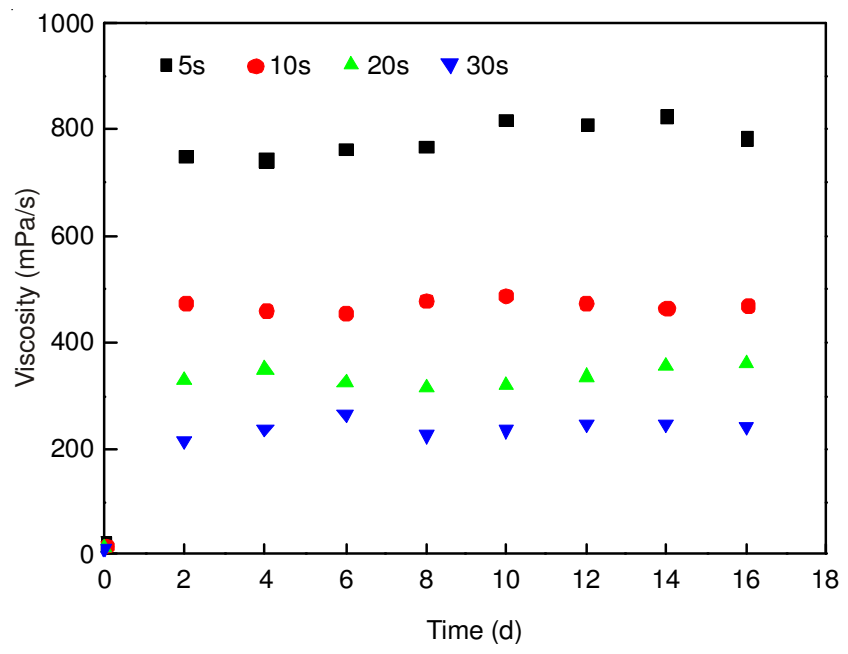

Fig. 6. Effect of shearing time on the viscosity of hydrophobically associating polymer solution

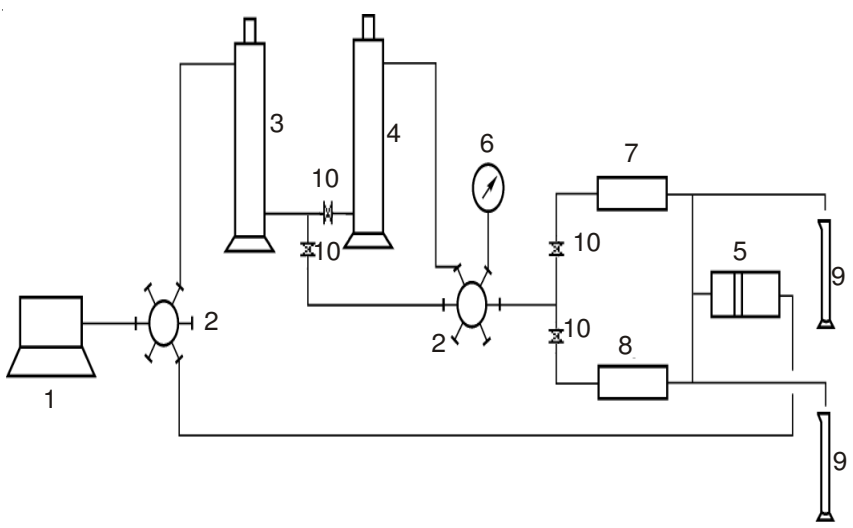

Fig. 7. Oil displacement experiment flow chart, 1-pump; 2-valve; 3-water container; 4-oil container; 5-intermediate container; 6-pressure meter 7-hypotonic sand-packing model; 8-hypertonic sand-packing model; 9-graduated test-tube; 10-valve

flood until effluent water cut is around to $98 \%$; (4) inject 0.3 PV self-polymer solutions; (5) put two sand packs into oven for $48 \mathrm{~h}$ under $40^{\circ} \mathrm{C}$; (6) water flood until effluent water cut is around $98 \%$ again; (7) calculate oil recovery increment;

The recovery rate of water flooding is about $35 \%$ while final recovery rate is about $48.3 \%$. Enhancement in oil recovery rate is $13.3 \%$ (Fig. 8).

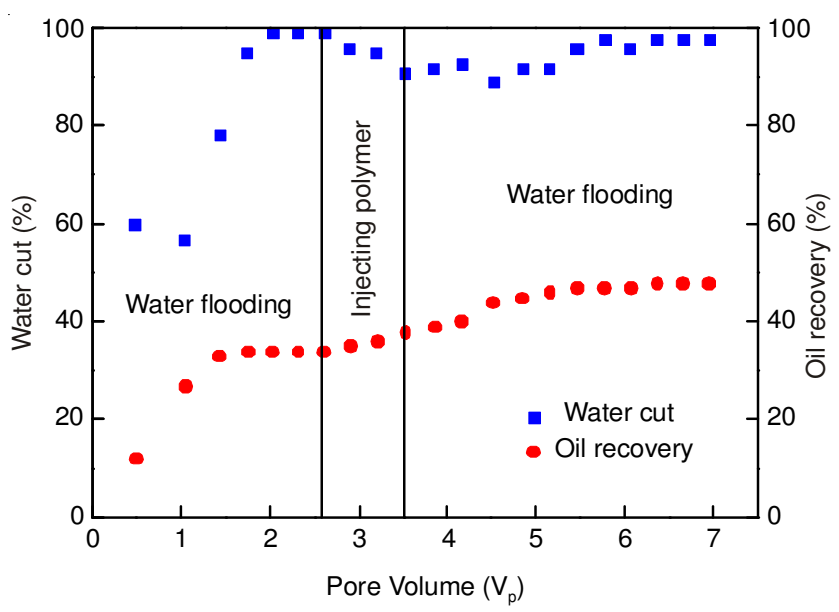

Fig. 8. Relationship between water cut/oil recovery and injecting pore volume

\section{Conclusion}

The properties of hydrophobically associating polymer were studied in this paper. The hydrophobically associating polymer has remarkably improved the properties of saltresistance and temperature-resistant. The applicable conditions are optimized and the opportunity for subsequent water flooding is determined which has practical meaning for oilfield application. Anti-shearing and oil displacement experiment shows its pretty good performance in self-assemble behaviour and enhanced oil recovery.

\section{REFERENCES}

1. A. Bayoumi, N. Eleman, O. Kamal and M. Khairy, J. Can. Petrol. Technol., 36, 42 (1997).

2. P. Barreau, D. Lasseux, H. Bertin, Ph. Glenat and A. Zaitoun, SPE37303-MS, International Symposium on Oilfield Chemistry, 18-21 February, Houston, Texas, USA (1997).

3. W. Littmann, Polymer flooding. Amsterdam-Oxford-New York-Tokyo: Elsevier, 3-9 (1988).

4. J. Chatterji and J.K. Borchardt, J. Petrol. Technol., 33, 2042 (1981).

5. K.S. Sorbie, Polymer-Improved Oil Recovery. CRC Press, Inc., Boca Raton, Florida, USA, (1991).

6. J. Liu and R.S. Seright, Paper SPE 59318 presented at the SPE/DOE Improved Oil Recovery Symposium, Tulsa, Oklahoma, USA, April 3-5 (2000).

7. L. Ye, K.F. Luo and R.H. Huang, Eur. Polym. J., 36, 1711 (2000).

8. K.C. Taylor and H.A. Nasr-El-Din, J. Petrol. Sci. Eng., 19, 265 (1998).

9. G.O. Yahaya, A.A. Ahdab, S.A. Ali, B.F. Abu-Sharkh and E.Z. Hamad, Polymer, 42, 3363 (2001).

10. C.L. McCormick, T. Nonaka and C.B. Johnson, Polymer, 29, 731 (1988). 